\title{
Games, Design and Assessment: How Game Designers are Doing it Right
}

\author{
Stephen Bezzina \\ Ministry for Education and Employment, Malta \\ mail@stephenbezzina.com \\ DOI: 10.34190/GBL.19.114
}

\begin{abstract}
The fixation of formal education to measure and certify academic attainment, continues to fuel the ubiquity of standardised assessment procedures. As such, educators are reluctant to embrace the same constructivist and novel stance adopted towards learning to the assessment domain and continue to favour summative over formative practices. On the other hand, literature on games in education, suggests that well-designed digital games support and enhance the positive interplay between the different forms and functions of assessment, which are inherent to the learning environment. This paper examines the principles of good game design in light of the constructive interaction that exists between learning and the different functions of assessment in games. For instance, levelling and collecting badges whilst climbing up the ladder of challenges found in games, can be considered as the outcome of a purely summative assessment of the player's progress, as the information collected during gameplay is solely used to judge and certify the player's performance. However and more importantly, both for the game designers and the players, the game is continuously producing immediate performance feedback in the form of, amongst others, both on-demand and just-in-time information, which informs the players' learning and allows them to adjust their actions, thus serving as a formative assessment of gameplay. On analysing the respective literature in the field of game studies and assessment, this paper discusses a number of game elements and core mechanics, under three broad themes, namely (i) adaptivity (ii) feedforward and (iii) distributed cognition, which game designers successfully deploy in good game designs. These are gradually and naturally extended towards the theoretical and practical underpinning of an assessment for learning pedagogy, thus potentially informing and transforming traditional assessment practices into a more playful experience.
\end{abstract}

Keywords: games, learning, assessment, adaptivity, feedforward, distributed cognition

\section{Introduction}

The quantification of learning and the processes of measuring and certifying academic achievement remain the fixation of formal educational institutions (Bryan \& Clegg 2006; Hazelkorn 2014). Throughout the years, testdriven curricula have led assessment practices to endure a meagreness of pedagogical innovation and transformation (Whitelock \& Watt 2008). This has in turn led educational institutions to favour summative over formative practices, in view of both internal and external institutional consistency, accuracy and accountability. Furthermore, both educators and students have come to clearly distinguish between moments of learning and assessment, since the latter quite often carry important consequences for both the assessor and the assessed. On the other hand, literature on games in education, suggests that well-designed digital games can support different forms and functions of assessment, which are both intrinsic and complementary to the learning environment (Shute 2011; Smith et al. 2019). In fact, games provide excellent contexts where moments of both summative and formative assessment co-occur alongside deep and meaningful learning.

\section{Assessment}

Any kind of instructional effort requires at its core, a solid assessment framework (Brown \& Knight 1994; Taras 2005). Nevertheless, the means by which assessment is specified, designed and carried out is significantly subject to the objective and also perspective taken on by the respective stakeholders; including the policymakers, parents and most of all educators and students (Bloxham \& Boyd 2007, Bretag et al. 2018). In defining assessment, Sadler (1998) and McDonald and Boud (2003) focus on the active and indispensable role of the students, as in order to work with and understand definite assessment criteria, they are to evaluate their actual degree of proficiency vis-à-vis these requirements (Sadler 1989). In contrast, Pellegrino and colleagues (2001) and Popham (2006), emphasise the capacity of educators as sole receivers of information on students' understanding and knowledge, resulting from assessment. This gave rise to differing forms and functions of assessment, supported by viewpoints based on theories of learning and assessment (Bloxham \& Boyd 2007). Initially, two comprehensive purposes and objectives of evaluation in educational programme design, specifically those possessing summative and formative functions, were put forward by Scriven (1967). In its fundamental form, a summative assessment usually takes place at the end of a learning experience, in order to measure and certify students' proficiency for purposes of accreditation and (more recently) accountability (Torrance \& Pryor 1998). On the other hand, formative assessment occurs during a learning experience, whereas 
information resulting from tasks undertaken by students and/or educators, is used to adapt and adjust future learning and teaching (Black \& Wiliam 1998).

Throughout the years, the adoption of standardised assessment procedures has regulated the propensity of educators to develop and implement engaging assessment pedagogies in their classrooms. Mainly fuelled by the longstanding internal and external institutional demands for consistency, comparison and accountability (Brown \& Knight 1994), this has led to a narrowed and test-driven curriculum, which has consequently limited the skills, competences and content learnt by the students (David 2011, Goldhaber 2018). The overemphasis of standardised assessment continues to force educators to do away with creative and innovative assessment activities in view of a normalised and quite often scripted format. As such, formal academic achievement, mostly in the form of summative high-stakes centralised examinations used to define, measure and monitor students' progress in terms of set educational criteria, continues to dominate formal education (Sion 2004). As an unintended outcome, students have learnt to learn for an examination, which is in turn reflected in both the selection and caliber of learning that transpires (Boud 1995; Everaert et al. 2017). This usually contributes to surface learning approaches, in both the motive and strategy utilised (Scouller 1998).

In fact, summative assessment in the form of high-stakes examinations, has become an end in itself rather than as a means to obtain information and evidence to inform subsequent action, as opposed to a more formative approach. Furthermore (and even more worryingly), both educators and students have come to clearly distinguish between moments of learning and assessment, since the latter carry important consequences for both the assessor and the assessed. Quite often, class-based everyday formative assessment activities, are considered to be 'soft' assessment tasks which carry little or no value. Unfortunately, such formative efforts are filtered by the purposes brought about by standardised summative testing, defined by and directly dependent upon singular end of semester/year examination performances. As such, in preparing their students for examinations, educators have come to regard summative assessment as a necessary evil and are increasingly reluctant to embrace the same formative and constructivist stance adopted towards learning to the assessment domain.

\section{Games and assessment}

Throughout the years, games have seen considerable improvements in their respective processing techniques, platforms and consoles mainly due to the deployment of emerging technologies (Caserman et al. 2018; Salen \& Zimmerman 2004). Amongst others, this has led to rapid improvements in the feedback mechanisms, inter-and intra-game communication, character development and the immersive storytelling surrounding gameplay (Salen \& Zimmerman 2004). Albeit at times used for repeating and recalling facts, games can be especially valuable in cultivating more complex proficiencies (Gee 2007), through their ability of sustaining and applying 'high-level transferable skills - such as analysis, critical evaluation, autonomy, and team working' (Whitton 2009, p.45) during gameplay. This makes games constructivist learning environments (Franco \& DeLuca 2019; Klopfer et al. 2009), where learning 'matches up very well with emerging cognitive science research on how people think and learn' (Squire 2005, p.7)

Although primarily, game studies literature in the field of education focuses on teaching and learning (Steinkuehler 2010; Sykes, 2018), recent and current research corroborates the idea of games for assessment purposes, which is 'woven directly and invisibly into the fabric of the learning environment' (Shute \& Ke 2012, p.53). More commonly referred to as stealth assessment (Shute \& Ventura 2013), the information gathered on the players' actions and interactions during gameplay, goes beyond the mere tracking of experience points or levels in a game and does not interrupt the players' experience of flow or the state of immersion where 'nothing else seems to matter' (Csíkszentmihályi 1990, p.4). Instead this form of embedded assessment, gives a noninvasive, yet targeted evaluation of the players' skills and abilities in performing predefined tasks inside the game world. This contributes towards a holistic and comprehensive assessment of the player's overall performance in terms of pre-defined learning objectives. Apart from traditional content-related outcomes, this form of assessment in games could also be potentially used to measure and monitor other important skills like creativity, scientific inquiry and persistence (Shute \& Ventura 2013; Taub \& Azevedo 2018). The resulting information from this evidence-based approach, can be eventually processed by the system and used as a diagnostic and formative tool by the educators. For instance, in ARTé: Mecenas ${ }^{\mathrm{TM}}$, an Art History game by Triseum, the automated collection and analysis of cumulative data, provides educators with immediate access to the most consistent 


\section{Stephen Bezzina}

and up-to-date information on the students' progress, on which they can act in a timely manner, to potentially improve teaching and learning.

\section{Games, design and assessment}

In order to achieve 'a quiet, yet powerful process by which learner performance data are continuously gathered' (Shute 2011, p.504) during gameplay, designers successfully deploy a number of game elements together with methods 'through which players make meaningful choices and arrive at a meaningful play experience' (Salen \& Zimmerman 2004, p.317). These core mechanics are particularly relevant in a stealth assessment process as they define the players' experiential cycle and hence give rise to specific data points within the game (Shute 2011).

In this section, a number of key game elements and core mechanics which are successfully deployed in good game designs are described under three broad main themes, namely (i) adaptivity (ii) feedforward and (iii) distributed cognition. These are discussed in terms of their theoretical and practical implications with respect to an assessment for learning pedagogy in and out of the game world.

\subsection{Adaptivity}

The early stages in good games normally represent 'simplified versions of the same world in which the player will live, play, and learn throughout the game' (Gee 2007, p.123). In the first levels of DragonBox Numbers, which actually serve as 'fish tanks' (Gee 2004, p.9), the player is gradually introduced to Nooms - the characters that each represent a number between 1 and 10. Through combining, slicing and comparing, the player can build and slowly master number sense, before proceeding to the next and more difficult levels. As the player advances, the game has the ability to adapt to the current performance level and reward each player, regardless of the level of competency reached (Gee 2007). In particular, game designers use player modeling methods to detect, model, predict and express 'human player characteristics which are manifested through cognitive, affective and behavioural patterns' (Yannakakis et al. 2013, p.45). This use of artificial and computational intelligence techniques supports the core game mechanics, which in turn gives rise to patterns of meaningful learning and actions enacted by the players during gameplay. The resulting data and consequently evidence on the players' mastery, can be potentially 'stored in a dynamic model of the learner' (Shute 2011, p.504), hence providing an up-to-date profile for each individual student.

On the other hand, standardised means of assessment are generally generic and static and still largely dominated by a one-size-fits-all postulation which must be challenged in pursue of a more inclusive and personal mode of assessment (Joint Information Systems Committee (JISC) 2007). One such attempt is represented by the principle behind computer adaptive testing (CAT), where the assessed starts at a moderate level or 'concentrated sample' (Gee 2007, p.142) and proceeds according to the performance on the preceding test items (Challis 2005). As such, the learner level is constantly established as the skills and knowledge required in CAT are found within the outer periphery of the 'regime of competence' (Gee 2007, p.68) of the individual students. The bottom-up and well-ordered problem environment in CAT, as well as in games, allows the learners to monitor their progress (Chong 2018; Crooks 1988) and boosts the pleasant frustration experienced (Gee 2004) in climbing the 'ladder of challenges' (Greenfield 1984, p.110) posed by the assessment task.

The scaffolding strategy found in highly responsive environments, promotes a replay and practice philosophy (Gee 2007; Liao et al. 2019), where the players, as well as the learners, learn to fail better each time. In fact, CAT successfully embodies good game designs in terms of game elements and core mechanics, as it recognises the diverse ways of learning (Chickering \& Gamson 1991) and provides multiple roots to make progress where learning becomes a 'cycle of expertise' (Gee 2004, p.20). Moreover, CATs can be designed to end when the learner reaches a particular level of proficiency and in the process generate learning resources, targeted at the level of the individual student (Bull \& McKenna 2004). This facilitates learning strategies, whilst delivering relevant information to students about their learning, aimed at closing the gap between the current and required performance (Nicol \& Macfarlane-Dick 2006). Such levels of personalisation and adaptivity in assessment processes can potentially lead to an increased level of motivation due to the customizability of user experience. In fact, motivational researchers argue that, amongst others, intrinsically enjoyable learning situations include elements of challenge and control (Malone 1980). This may well be regarded as a state of optimal learning, which is characterised by contexts that offer intensive interaction, have goals and procedures, are motivating, challenging and engaging and provide the appropriate tools to the learner (Norman 1993). 


\subsection{Feedforward}

Traditionally, the term feedback is used in education to refer to the information resulting from 'a consequence of performance' (Hattie \& Timperley 2007, p.81). This naturally assumes a reactive role as it is focussed on the past. In 1951, Ivor Armstrong Richards coined the term feedforward (Richards 1951), which in behavioural and cognitive sciences translates to the provision of information which informs forthcoming teaching and learning (Carless 2007). Such a proactive disposition to direct future activity, based on past and present performances, is an extremely important game element, and forms the basis for the interrelated patterns of actions in core mechanics.

As such, levelling up in a game by moving around, managing resources and solving quests, is a tangible sign of progression (Greenfield 1984). Improvement and consequently progress, are only usually possible through the information generated by the game, which is both in time and on demand (Gee 2004). However, unless acted upon by the player, such data would offer feedback which has the same effect as in traditional assessment practices and is still considered a major concern and source of dissatisfaction for students in higher education (Hounsell 2007). Students' discontent with feedback mechanism in educational institutions, varies from the timing to the frequency, consistency and the perceived usefulness and guidance obtained throughout (Hounsell 2007).

This highly contrasts with the immediate performance feedforward afforded by games (Malone 1982). The resulting information is both formative and constructive, and is indispensable in directing the players' actions towards the end goal (Malone 1980). This is because it does not merely focus on past and present performances but naturally assumes a high value disposition (Hounsell 2007) by adopting a feedforward nature (Carless 2007; Gibbs \& Simpson 2004; Malthouse \& Roffey-Barentsen 2018). All learners, very much as all players, need ongoing, timely and formative information on their learning (Gibbs \& Simpson 2004; Shute 2007). This helps both learners and players to act on any feedback received (Carless 2007; Gibbs \& Simpson 2004) and program the next course of actions (Gee 2004), while it allows for a greater degree of autonomy and responsibility. In fact, self-regulating strategies (Cleary 2018; Nicol \& Macfarlane-Dick 2006) are essential for closing the loop in games, as much as in assessment (Sadler 1989). Digital learning and assessment environments afford a substantial shift in emphasis from feedback to feedforward, starting from a greater effectiveness and flexibility in producing and publishing information on learning (Crossouard \& Pryor 2009). For instance, well-crafted online multiple choice questions (through the use of hints, additional information and correct answers) can have an accelerant effect on learning (Hounsell 2007) by providing real-time feedforward and thus act as a catalyst for further improvement in performance (Black et al. 2003). Such data resulting from learning, moves beyond the simplistic provision of scores and marks, but supports the students in becoming fully immersed in a cycle of knowledge and understanding, bridging the gap between assessment and learning - pretty much what happens in games.

\subsection{Distributed cognition}

Players achieve expertise in games through independent as well as collaborative efforts (Squire 2008; Steinkuehler 2004). Both knowledge and skills do not reside solely in the player, but are distributed across the individual, peers and in the various surrounding tools and technologies. This implies that learning and assessment are a social practice and a direct result of the various actions and interactions surrounding the learning environment (Davies 2009). For instance, massively multiplayer online role-playing games (MMORPGs), like World of Warcraft, allow players to work together in guilds in order to explore landscapes and solve quests in a truly collaborative environment (Ke 2019; Kiili 2005). In particular, MMORPGs, help players to develop valuable communication and critical thinking skills, while effectively learning from others (Whitton 2009). Apart from encouraging collaboration, these also provide a context for peer-interaction and dialogue (Nicol \& Macfarlane-Dick 2006), while allowing for the emergence of affinity groups and communities of practice (Gee 2007), both in and out of the game world. Such game elements and core mechanics are extremely important in view of a collaborative approach to stealth assessment techniques, where sequences of actions are shared with other players and the surrounding environment. Hence, individual students complement each other in endeavour to develop a shared understanding of knowledge (Hargreaves 2007). This socially constructed form of knowledge allows the students to test their hypothesis with their peers, receive valuable feedback and thus effectively explore their own learning in a short period of time (Willey \& Gardner 2010). Real-time evidence resulting from these interactions within the game world, highly contrasts with the product approach to assessment as this analytic activity corroborates a process-driven and dynamic form of evaluation. 


\section{Stephen Bezzina}

Distributed cognition in games is made possible through the affordances provided by the authentic and embodied ways of gameplay (Gee 2007; Reinhardt 2019). Meaning in games is neither general nor decontextualized, but is instead situated in the words, actions and surrounding environment (Gee 2007). This highly contrasts with certain assessment of learning practices which amongst other tend to be inauthentic and context independent (Birenbaum et al. 2006). Assessment in games extends the notion of situated cognition (Brown et al. 1988) through the use of authentic assessment strategies (Rust 2007), where the demonstration of 'candidates' real life performance skills' (Whitelock \& Cross 2012, pp.2-3), is more important than the mere reproduction of knowledge in a 'non-authentic curriculum' (Knight 2002, p.281). Games can be used as platforms for authentic assessment activities, like role-play, as these allow learners to engage in a perceived-real world through different intrinsic fantasy elements (Malone 1980) by taking on a virtual identity (Cano et al. 2019; Gee 2007) or character role (de Freitas 2006). By providing a situated and distributed learning and potentially assessment environment, games support the unfolding of tasks through the choices and strategies adopted by the player and distributed amongst other players and surrounding tools. This allows for an active participation in assessment (Bryan \& Clegg 2006), where the learner can practice (Crooks 1988) in an authentic representation (Boud \& Falchikov 2006) and is thus encouraged to 'think, act, and value like a professional' (Gee 2005, p.2) in the process of developing the necessary expertise.

\section{Conclusion}

Games have the potential to act as transformative learning tools (Shute \& Ke 2012, Vervoort 2019). They can host educational content, as well as act as catalysts in promoting more complex competencies, such as applying skills, developing strategies, analysing information, evaluating situations and changing attitudes (Whitton 2009). In contrast to traditional standardised assessment, game designers have managed to both measure and enhance these learning experiences, by seamlessly recording gameplay data resulting from the deployment of particular game elements and core mechanics. The resulting information can be viewed as the outcome of a purely summative assessment of the player's progress, when the data collected during gameplay is solely used to judge and certify the player's performance. However and more importantly, both for the game designers and the players, the game is continuously producing important information which informs the players' learning and allows them to adjust their actions, thus serving as a formative assessment of gameplay. This game design approach to an assessment for learning, further reinforces the mutual relationship existing between summative and formative evaluations, as fundamentally, any form of assessment is a 'moment of learning' (Black \& Wiliam 1998, p.30), since both are the 'ends of the same continuum' (Brown 1999, p.6). This paper, underpinned by an assessment for learning philosophy in 'which the first priority in its design and practice is to serve the purpose of promoting students' learning' (Black et al. 2004, p.10), contributes interesting insights to the body of knowledge and practice in the fields of game studies and assessment. More than a pedagogical novelty, the theoretical foundations presented in the paper represent a critique and an attempt of philosophical shift in current assessment practices. This is informed by game elements found in good game designs, such as goals, points, levels, challenges, context, control and rewards. Together with the provision of core mechanics powered by different interrelated patterns of action, this results in individual player styles, directed by the constant information resulting from gameplay. Broadly categorised under three main themes, namely (i) adaptivity (ii) feedforward and (iii) distributed cognition, the arguments presented are aimed at potentially informing and transforming traditional assessment practices into a more playful experience.

\section{References}

Birenbaum, M. et al., 2006. A learning Integrated Assessment System. Educational Research Review, 1(1), pp.61-67.

Black, P. et al., 2004. Working inside the Black Box: Assessment for Learning in the Classroom. Phi Delta Kappan, 86(1), pp.8-21.

Black, P., Harrison, C. \& Lee, C., 2003. Assessment For Learning: Putting it into Practice, McGraw-Hill Education (UK).

Black, P. \& Wiliam, D., 1998. Assessment and Classroom Learning. Assessment in Education: Principles, Policy \& Practice, 5(1), pp.7-74.

Bloxham, S. \& Boyd, P., 2007. Developing Effective Assessment In Higher Education: A Practical Guide: A Practical Guide, McGraw-Hill Education (UK).

Boud, D., 1995. Assessment and learning: contradictory or complementary. Assessment for learning in higher education, pp.35-48.

Boud, D. \& Falchikov, N., 2006. Aligning assessment with long-term learning. Assessment \& Evaluation in Higher Education, 31(4), pp.399-413.

Bretag, T., Harper, R., Burton, M., Ellis, C., Newton, P., van Haeringen, K., Saddiqui, S. and Rozenberg, P., 2019. Contract cheating and assessment design: exploring the relationship. Assessment \& Evaluation in Higher Education, 44(5), pp.676-691. 
Brown, J.S., Collins, A. \& Duguid, P., 1988. Situated Cognition and the Culture of Learning.

Brown, S., 1999. Institutional strategies for assessment. In Assessment matters in higher education: Choosing and using diverse approaches. In S. Brown \& A. Glasner, eds. Assessment matters in higher education: Choosing and using diverse approaches. Buckingham: Open University Press, pp. 3-13.

Brown, S. \& Knight, P., 1994. Assessing Learners in Higher Education, Routledge.

Bryan, C. \& Clegg, K., 2006. Innovative Assessment in Higher Education, Routledge.

Bull, J. \& McKenna, C., 2004. Blueprint for Computer-assisted Assessment, Psychology Press.

Carless, D., 2007. Learning-oriented assessment: conceptual bases and practical implications. Innovations in Education and Teaching International, 44(1), pp.57-66.

Cano, J.H.M., Lopez, J.P.M. and Posada, D.M.O., 2019, March. Phenomenographic Study on the Teaching-Learning of Entrepreneurship through the use of Role Playing Games. In Developments in Business Simulation and Experiential Learning: Proceedings of the Annual ABSEL conference (Vol. 46).

Caserman, P., Tregel, T., Fendrich, M., Kolvenbach, M., Stabel, M. and Göbel, S., 2018, November. Recognition of Full-Body Movements in VR-Based Exergames Using Hidden Markov Models. In Joint International Conference on Serious Games (pp. 191-203). Springer, Cham.

Challis, D., 2005. Committing to quality learning through adaptive online assessment. Assessment \& Evaluation in Higher Education, 30(5), pp.519-527.

Chickering, A.W. \& Gamson, Z.F., 1991. Seven principles for good practice in undergraduate education. New Directions for Teaching and Learning, 1991(47), pp.63-69.

Chong, S.W., 2018. Three paradigms of classroom assessment: Implications for written feedback research. Language Assessment Quarterly, 15(4), pp.330-347.

Cleary, T.J., 2018. The self-regulated learning guide: Teaching students to think in the language of strategies. Routledge.

Crooks, T.J., 1988. The Impact of Classroom Evaluation Practices on Students. Review of Educational Research, 58(4), p.438.

Crossouard, B. \& Pryor, J., 2009. Using email for formative assessment with professional doctorate students. Assessment \& Evaluation in Higher Education, 34(4), pp.377-388.

Csíkszentmihályi, M., 1990. Flow: The Psychology of Optimal Experience, New York: Harper and Row.

David, J., 2011. What students need to learn: high-stakes testing narrows the curriculum. Educational leadership: journal of the Department of Supervision and Curriculum Development, N.E.A, 68(6), pp.78-80.

Davies, W.M., 2009. Groupwork as a form of assessment: common problems and recommended solutions. Higher Education, 58(4), pp.563-584.

de Freitas, S., 2006. Learning in Immersive Worlds: A Review of Game-based Learning,

Everaert, P., Opdecam, E. and Maussen, S., 2017. The relationship between motivation, learning approaches, academic performance and time spent. Accounting Education, 26(1), pp.78-107.

Franco, P.F. and DeLuca, D.A., 2019. Learning through action: Creating and implementing a strategy game to foster innovative thinking in higher education. Simulation \& Gaming, 50(1), pp.23-43.

Gee, J.P., 2005. Learning by Design: Good Video Games as Learning Machines. E-Learning and Digital Media, 2(1), pp.5-16.

Gee, J.P., 2004. Situated Language and Learning: A Critique of Traditional Schooling, Routledge.

Gee, J.P., 2007. What video games have to teach us about learning and literacy, New York: Palgrave Macmillan.

Gibbs, G. \& Simpson, C., 2004. Conditions under which assessment supports students' learning. Learning and teaching in higher education, 1(1), pp.3-31.

Goldhaber, D., 2018. A Gloomy Perspective on High-Stakes Testing. Education Next, 18(2).

Greenfield, P., 1984. Video Games. In Mind and Media: The Effects of Television, Video Games, and Computers. Cambridge Mass: Harvard University Press, pp. 86-114.

Hargreaves, E., 2007. The validity of collaborative assessment for learning. Assessment in Education: Principles, Policy \& Practice, 14(2), pp.185-199.

Hattie, J. \& Timperley, H., 2007. The Power of Feedback. Review of Educational Research, 77(1), pp.81-112.

Hazelkorn, E., 2014. Reflections on a Decade of Global Rankings: what we've learned and outstanding issues. European Journal of Education, 49(1), pp.12-28.

Hounsell, D., 2007. Towards more sustainable feedback to students. In B. D. \& F. N., eds. Rethinking assessment in higher education. London: Routledge, pp. 101-113.

James Popham, W., 2006. Assessment for Educational Leaders, Allyn \& Bacon.

Joint Information Systems Committee (JISC), 2007. Effective Practice with e-Assessment: An overview of technologies, policies and practice in further and higher education. Joint Information Systems Committee.

Ke, F., 2019. Mathematical problem solving and learning in an architecture-themed epistemic game. Educational Technology Research and Development, pp.1-20.

Kiili, K., 2005. Digital game-based learning: Towards an experiential gaming model. The Internet and Higher Education, 8(1), pp.13-24.

Klopfer, E., Osterweil, S. \& Salen, K., 2009. Moving learning games forward: Obstacles, opportunities \& openness, Cambridge: The Education Arcade.

Knight, P.T., 2002. Summative Assessment in Higher Education: Practices in disarray. Studies in Higher Education, 27(3), pp.275-286. 


\section{Stephen Bezzina}

Liao, C.W., Chen, C.H. and Shih, S.J., 2019. The interactivity of video and collaboration for learning achievement, intrinsic motivation, cognitive load, and behavior patterns in a digital game-based learning environment. Computers \& Education, 133, pp.43-55.

Malone, T.W., 1982. Heuristics for designing enjoyable user interfaces. Proceedings of the 1982 conference on Human factors in computing systems.

Malone, T.W., 1980. What makes things fun to learn? heuristics for designing instructional computer games. Proceedings of the 3rd ACM SIGSMALL symposium and the first SIGPC symposium on Small systems.

Malthouse, R. and Roffey-Barentsen, J., 2018. Can 'Feed-Forward' Work?. Academic Growth in Higher Education: Questions and Answers, p.130.

McDonald, B. \& Boud, D., 2003. The Impact of Self-assessment on Achievement: The effects of self-assessment training on performance in external examinations. Assessment in Education: Principles, Policy \& Practice, 10(2), pp.209-220.

Nicol, D.J. \& Macfarlane-Dick, D., 2006. Formative assessment and self-regulated learning: a model and seven principles of good feedback practice. Studies in Higher Education, 31(2), pp.199-218.

Norman, D.A., 1993. Things that Make Us Smart: Defending Human Attributes in the Age of the Machine, Basic Books.

Pellegrino, J.W., Chudowsky, N. \& Glaser, R., 2001. Knowing what students know: The science and design of educational assessment, Washington: National Academy Press.

Reinhardt, J., 2019. Gameful L2 Learning. In Gameful Second and Foreign Language Teaching and Learning (pp. 101-139). Palgrave Macmillan, Cham.

Richards, I.A., 1951. Communication between men: The meaning of language. In Cybernetics/Kybernetik: The MacyConferences 1946-1953. pp. 382-415.

Rust, C., 2007. Towards a scholarship of assessment. Assessment \& Evaluation in Higher Education, 32(2), pp.229-237.

Sadler, D.R., 1989. Formative assessment and the design of instructional systems. Instructional Science, 18(2), pp.119-144.

Sadler, D.R., 1998. Formative Assessment: revisiting the territory. Assessment in Education: Principles, Policy \& Practice, 5(1), pp.77-84.

Salen, K. \& Zimmerman, E., 2004. Rules of Play: Game Design Fundamentals, MIT Press.

Scouller, K., 1998. The influence of assessment method on students' learning approaches: Multiple choice question examination versus assignment essay. Higher Education, 35(4), pp.453-472.

Scriven, M., 1967. The Methodology of Evaluation. In R. Tyler, R. Gagne, \& M. Scriven, eds. Perspectives on curriculum evaluation. Chicago: Rand McNally and Co, pp. 38-83.

Shute, V.J., 2007. Focus on Formative Feedback. ETS Research Report Series, 2007(1), pp.i-47.

Shute, V.J., 2011. Stealth assessment in computer-based games to support learning. Computer games and instruction, 55(2), pp.503-524.

Shute, V.J. \& Ke, F., 2012. Games, Learning, and Assessment. Assessment in Game-Based Learning, pp.43-58.

Shute, V.J. \& Ventura, M., 2013. Stealth Assessment: Measuring and Supporting Learning in Video Games, MIT Press.

Smith, G., Shute, V. and Muenzenberger, A., 2019. Designing and Validating a Stealth Assessment for Calculus Competencies. Journal of Applied Testing Technology, 20(S1), pp.52-59.

Sion, R.T., 2004. A Standards Obsession: What Happened to Pedagogy? Kappa Delta Pi Record, 40(3), pp.100-103.

Squire, K., 2005. Game-Based Learning: An X-Learn Perspective Paper, MASIE center: e-Learning Consortium Report.

Squire, K., 2008. Video game literacy: A literacy of expertise. In J. Coiro et al., eds. Handbook of research on new literacies. Mahwah: Lawrence Erlbaum Publishers, pp. 635-670.

Steinkuehler, C., 2010. Video Games and Digital Literacies. Journal of Adolescent \& Adult Literacy, 54(1), pp.61-63.

Steinkuehler, C.A., 2004. Learning in massively multiplayer online games. In Y. B. Kafai et al., eds. Proceedings of the Sixth International Conference of the Learning Sciences. Mahwah: Erlbaum, pp. 521-528.

Sykes, J.M., 2018. Digital games and language teaching and learning. Foreign Language Annals, 51(1), pp.219-224.

Taras, M., 2005. Assessment - Summative and Formative - Some Theoretical Reflections. British Journal of Educational Studies, 53(4), pp.466-478.

Taub, M. and Azevedo, R., 2018. Using Sequence Mining to Analyze Metacognitive Monitoring and Scientific Inquiry based on Levels of Efficiency and Emotions during Game-Based Learning. JEDM Journal of Educational Data Mining, 10(3), pp.1-26.

Torrance, H. \& Pryor, J., 1998. Investigating Formative Assessment: Teaching, Learning and Assessment in the Classroom, McGraw-Hill Education (UK).

Vervoort, J.M., 2019. New frontiers in futures games: leveraging game sector developments. Futures, 105, pp.174-186.

Whitelock, D. \& Cross, S., 2012. Authentic assessment: What does it mean and how is it instantiated by a group of distance learning academics? International Journal of e-Assessment, 2(1).

Whitelock, D. \& Watt, S., 2008. Reframing e-assessment: adopting new media and adapting old frameworks. Learning, Media and Technology, 33(3), pp.151-154.

Whitton, N., 2009. Learning and Teaching with Computer Games in Higher Education. Games-Based Learning Advancements for Multi-Sensory Human Computer Interfaces, pp.18-33.

Willey, K. \& Gardner, A., 2010. Investigating the capacity of self and peer assessment activities to engage students and promote learning. European Journal of Engineering Education, 35(4), pp.429-443.

Yannakakis, G.N. et al., 2013. Player Modeling. In S. M. Lucas et al., eds. Artificial and Computational Intelligence in Games. pp. 45-59. 